\title{
INFLUENCE OF THE ARRANGEMENT OF MATERIALS AND MICROSTRUCTURAL ANALYSIS DURING FSW OF AZ80A \& AZ91C Mg ALLOYS
}

\begin{abstract}
The main objective of this paper is to produce defect free weldments with improved properties during friction stir welding of dissimilar Mg alloys. The influence of the anisotropic arrangement of materials when AZ80A Mg alloy is taken as advancing side and AZ91C Mg alloy as retreating side and vice versa with respect to their mechanical properties and microstructural characteristics were investigated. The effects of various FSW parameters on the quality of these joints were also analyzed and best optimized FSW parameters were suggested. Defect free sound joints with excellent mechanical properties were produced when AZ80A Mg alloy was positioned at retreating side. At the same time, it seems a little bit difficult to obtain good quality joints with the contrary arrangement of materials. These investigations revealed that materials having inferior plastic deformability must be kept at the advancing side to obtain sound joints during FSW of dissimilar alloys of Magnesium.
\end{abstract}

Keywords: Mg alloy;Friction stir welding; anisotropic arrangement; advancing side; retreating side

\section{Introduction}

In the recent years, magnesium (Mg) alloys have earned greater demands as an alternative material for aerospace, ship building, automotive, electronic industrial applications [1]. This was mainly due to the promising characteristics of Mg alloys such as good corrosion resistance, high damping capacity, greater specific strength, excellent stiffness along with easy castability and desirable capability for enabling the recycling process [2]. The most commonly employed $\mathrm{Mg}$ alloys for the aerospace and automotive industries are the AZ91 alloys. Besides, their wider applications, these alloys are restricted for some applications because their strength is not high enough to meet the needs [3]. At the same time, AZ80 Mg alloys having high strength values are restricted to usage due to their deformation ability which is very poor [4]. Hence, joining of AZ80 and AZ91 Mg alloys can provide a new scope and increase their areas of applications in various industrial sectors.

Invented, developed \& patented in the year 1991 by The Welding Institute (TWI), Friction Stir Welding (FSW), is an incomparable, attractive, hot shear joining / welding technique comprising a rotating tool which is non consumable in nature [5]. Using FSW, weldments free from defects (including hot cracking, alloy segregation, porosity etc.,) with appreciable \& better mechanical properties and excellent surface finish are obtained in a variety of aluminium, copper, magnesium, titanium alloys, which were previously having some limitations \& constraints during their conventional welding processes [6]. Further, the need for the post welding cleaning of the alloys is completely eliminated when the alloys are welded using FSW. Moreover, the absence of the melting of the base metal provides more benefits to the friction stir welding process compared with other conventional welding techniques [7].

\section{Literature review}

It was experimentally proved by many research investigations that the defects associated with the weldments obtained using traditional welding techniques are completely dismissed when employing FSW process. This incomparably broadens the scope of employing $\mathrm{Mg}$ alloys to numerous applications. Different alloys of Magnesium including AZ31, ZK60, AZ61, AM50 etc have been fabricated successfully by FSW process and numerous experimental investigations were conducted during the FSW of these Mg alloys [8-12]. For example, Rajakumar et al. [9] made an examination during FSW of ZK60 Mg alloys at an $800 \mathrm{rpm}$ rotation rate and $100 \mathrm{~mm} / \mathrm{min}$ traverse speed. During this investigation, it was proved that joining of ZK60 Mg alloys by FSW process has created notable refinement of grains in the stir zone leading to significant increase in the mechanical strength of the joint with the ultimate tensile strength reaching $87 \%$ of the base metal. Likewise, the experiments conducted by Zeng et al. [12] revealed us that the stir zone regions of the joints of AM50 Mg alloy fabricated using FSW were observed with the presence of recrystallized microstructure containing $\beta$ phase

\footnotetext{
S.A. ENGINEERING COLLEGE, CHENNAI, INDIA

* Corresponding author: drsevvel@saec.ac.in
} 
and $\alpha$-matrix. This has led to the reduction in the size of the grains at the nugget zone which contributed to the increase in the hardness of the fabricated joints. But the proclaimed knowledge on the FSW of dissimilar Mg alloys is very scant. Hence, a detailed experimental investigation on the FSW of dissimilar Mg alloys especially AZ80A and AZ91C is inevitable. In this experimental paper, a real endeavor was made to understand in detail, the transitions in the microstructural characteristics and modifications in the mechanical properties arising due to the anisotropic arrangement of the dissimilar Mg alloys.

\section{Details of experimental investigation}

\subsection{Base materials and equipment}

The base materials in this investigation are wrought AZ80A $\mathrm{Mg}$ alloy and cast AZ91C Mg alloy. The required thickness of $5 \mathrm{~mm}$ of the AZ80A magnesium alloy was obtained by machining AZ80A wrought plate of composition (in wt\%): $\mathrm{Al}-7.8$; $\mathrm{Zn}$ - 0.7; $\mathrm{Mn}$ - 0.3; Cu - 0.05; Si - 0.1; Fe-0.005; Ni - 0.005; $\mathrm{Mg}$ - balance and AZ91C was subjected to casting process to obtain a $5 \mathrm{~mm}$ thickness plate with composition of $9.14 \%$ Aluminium; 0.86\% Zinc; 0.30\% Manganese; 0.08\% Copper; 0.12\% Silicon; less than a $0.01 \%$ of Iron \& Nickel and balance being Magnesium. The dimensions of the base metals in this investigation are $150 \mathrm{~mm} \times 50 \mathrm{~mm} \times 5 \mathrm{~mm}$. The photographic view of the FSW machine (semi automatic) employed for performing this investigation is shown in the Fig. 1.

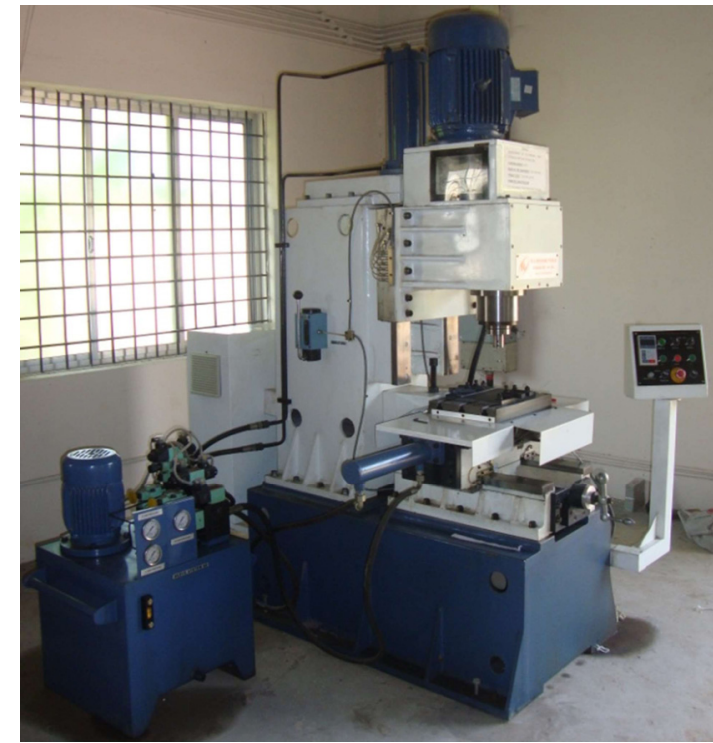

Fig. 1. Photographic View of the FSW Machine (Semi Automatic) employed in this investigation

\subsection{FSW tool and process parameters}

In this experimental research, a tool with cylindrical (taper) pin profile fabricated out of M35 High Speed Steel material with a shoulder diameter of $12 \mathrm{~mm}, 7-4 \mathrm{~mm}$ pin diameter (major to minor diameter) with a $4.75 \mathrm{~mm}$ pin length was employed as the FSW tool. The photographic representation of this taper cylindrical pin profiled tool employed in this investigation is illustrated in the Fig. 2.
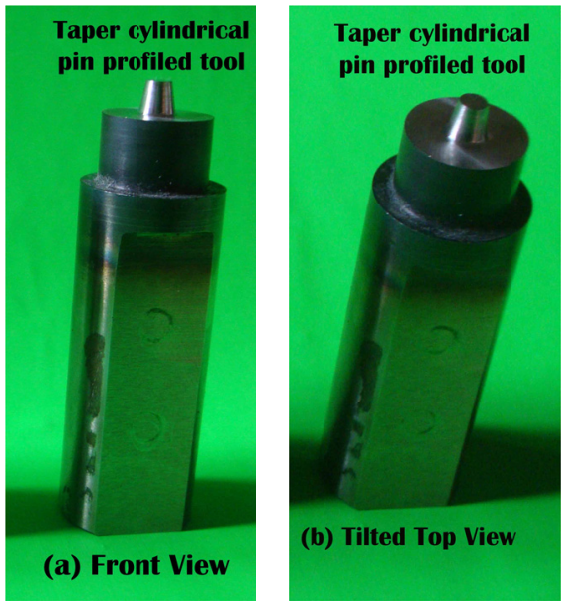

Fig. 2. Different photographic views of taper cylindrical pin profiled FSW tool used in this investigation

The experiments were carried out at different tool rotational speeds ranging from $200 \mathrm{rpm}$ to $1400 \mathrm{rpm}$ at various tool traverse speeds (feed rates) ranging from $0.5 \mathrm{~mm} / \mathrm{min}$ to $3.0 \mathrm{~mm} / \mathrm{min}$ along with a steady constant axial force value of $3 \mathrm{kN}$. The dissimilar AZ80A Mg and AZ91C Mg alloy flat plates to be joined using FSW were cleaned both chemically and mechanically using acetone before the welding process for elimination of any surface contamination.

\subsection{Anisotropic Arrangement of Base Plates}

The graphical representations and photographic view of the experimental set up adopted during the FSW of dissimilar Mg alloys namely AZ91C and AZ80A are shown in the Fig. 3. It can be seen that in the (Fig. 3a), the AZ80A Mg alloy was kept at the advancing side (AS) and in the (Fig. 3b), the AZ80A Mg alloy

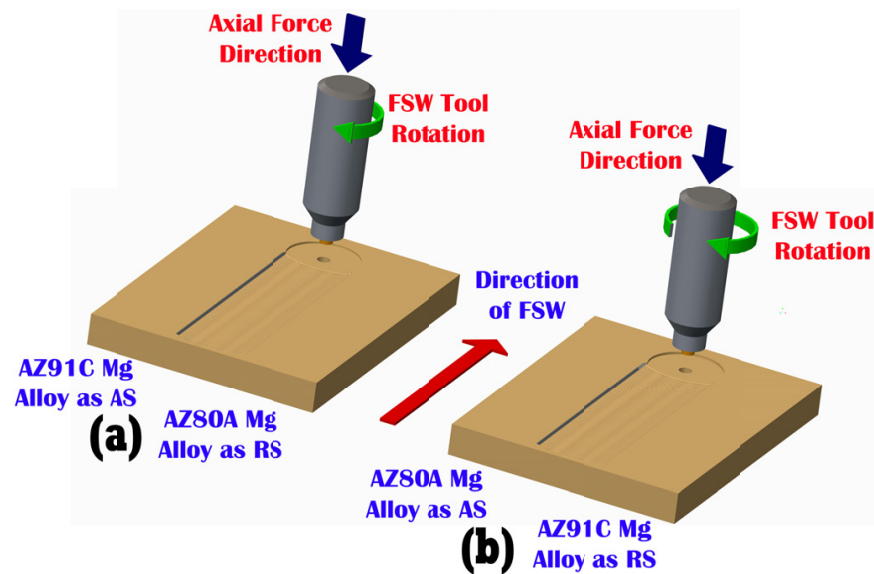

Fig. 3. Graphical representation of the experimental set up during FSW of dissimilar Mg alloys 

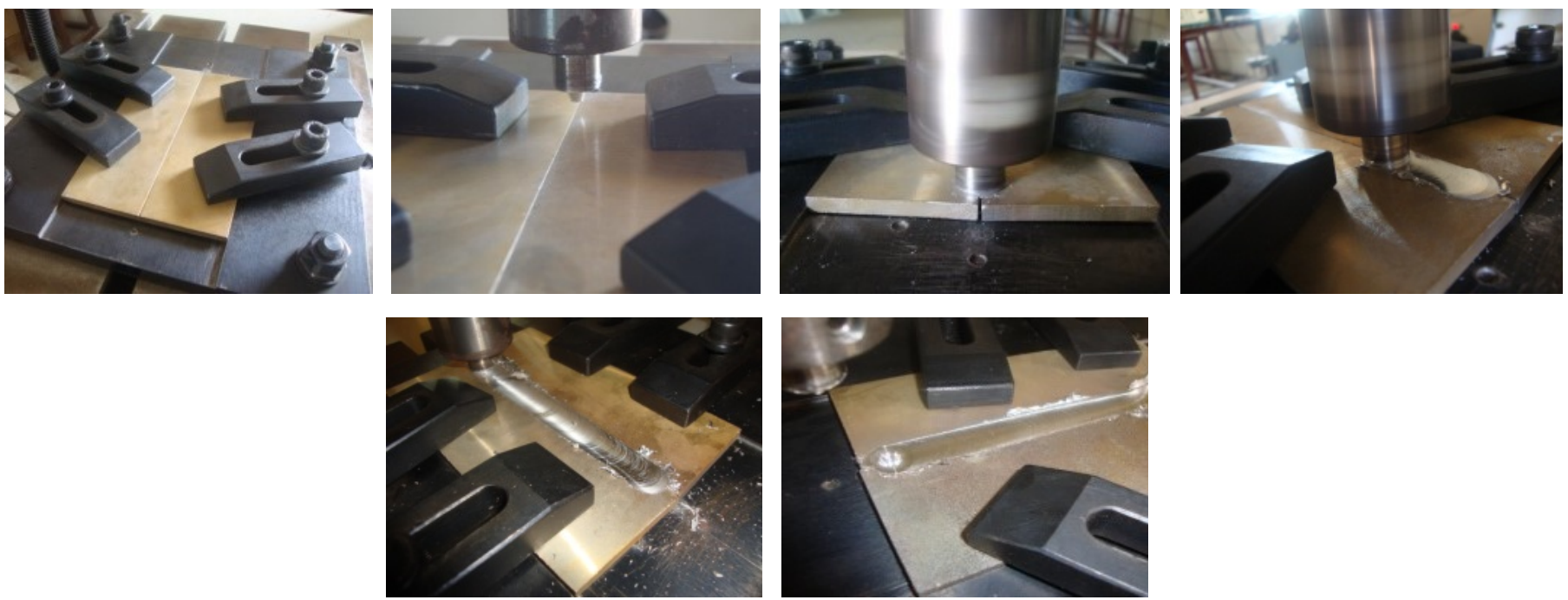

Fig. 4. Photographs of the various stages of FSW of dissimilar Mg alloys in the condition of AZ91C as the advancing side (AS) and AZ80A as the retreating side (RS)

was kept at the retreating side (RS). The movement of the FSW tool and its direction of rotation along the centerline of these two dissimilar Mg alloy flat plates are also represented in Fig. 3.

\section{Observations, results \& discussions}

\subsection{Fabrication of joints}

FSW of AZ80A/AZ91C Mg alloy joints (with AZ80A as AS) and AZ91C/AZ80A Mg alloy joints ((with AZ91C as RS) were carried out under various process parameters and Fig. 5 portrays a part of the joints fabricated during this experimental investigation.

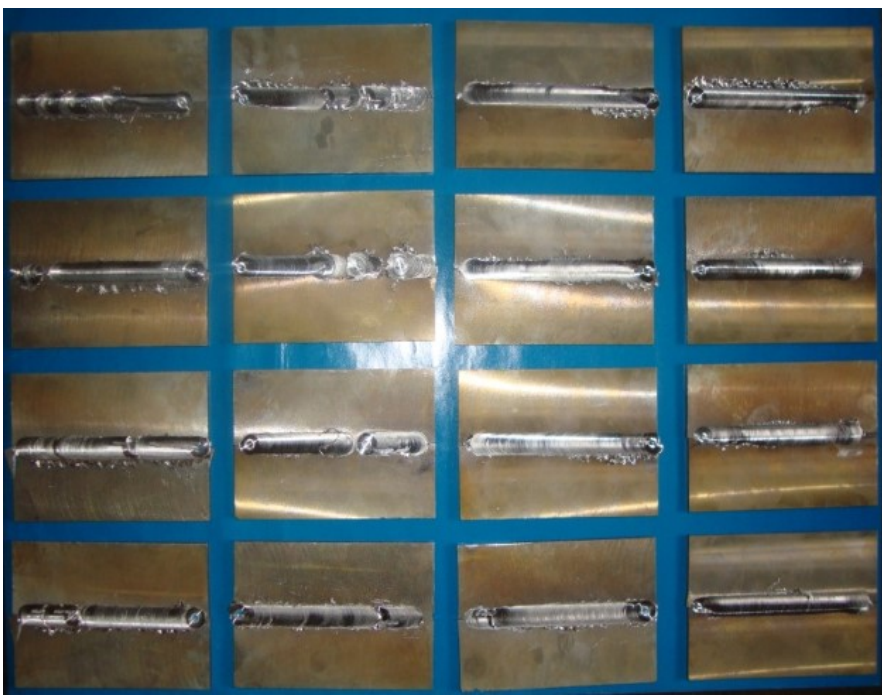

Fig. 5. Photographs of a part of the joints fabricated during this investigation under various process parameters using different pin profiled tools

Even though the surface of the fabricated joints appear to be defect free, defects including tunnel defects were found to present in the weld zone cross sections of some fabricated joints and the microstructural image test results for these weldments are illustrated in the Fig. 6. It can be visualized from the (Fig. 6a) that sound joints can be fabricated under various FSW process parameters with keeping AZ91C Mg alloy on AS.
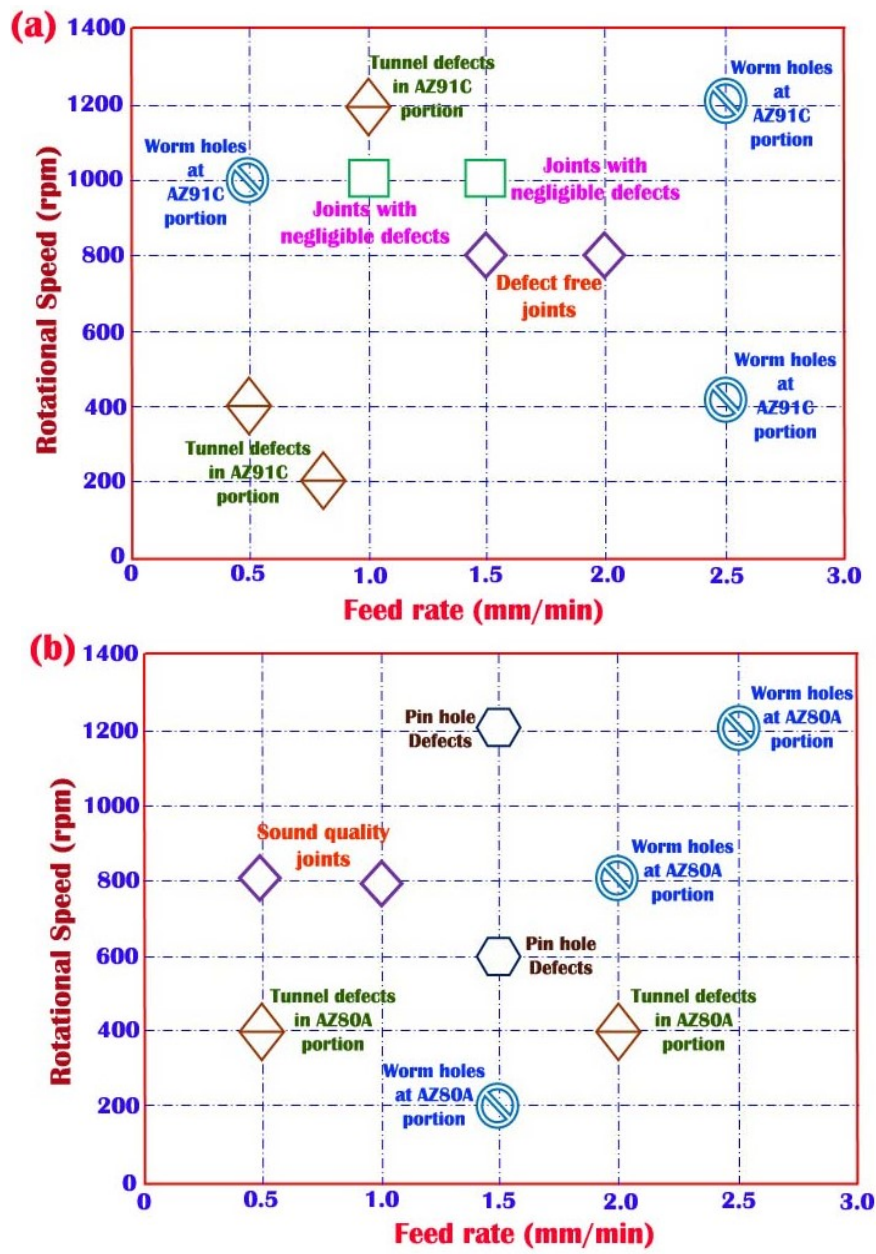

Fig. 6. Graphical representation of microstructural image test results for FSW of: (a) AZ91C/AZ80A joints and (b) AZ80A/AZ91C joints 
It can also be seen that when the feed rate was $0.5 \mathrm{~mm} / \mathrm{min}$ and as the tool rotational speed increased from $200 \mathrm{rpm}$ to $800 \mathrm{rpm} \&$ above $1000 \mathrm{rpm}$, defects like worm holes were observed in the fabricated joints at the AZ91C side. When the feed rate is increased from $0.5 \mathrm{~mm} / \mathrm{min}$ to $1.5 \mathrm{~mm} / \mathrm{min}$ and maintaining the tool rotational speed at a constant speed of $800 \mathrm{rpm}$, it is found that the joints are fabricated in better quality. Fig. 6b reveals us that keeping the AZ91C Mg at AS, in majority of the conditions, it was difficult to fabricate sound quality joints. Defects including worm holes, pin holes \& tunnel defects were noticed in majority of the joints. This indicates us that the appreciable difference can be seen in the quality of the joints when keeping different materials as the advancing side or as the retreating side under the same process parameters. This proves us the influence of arrangement of materials on the joints fabricated using FSW process.

\subsection{Microstructural Characteristics}

The macrostructural cross sections of the AZ80A/AZ91C joints and AZ91C/AZ80A joints fabricated under the optimized process parameters are shown in Table 1 . In the AZ91C/ AZ80A joints, as the feed rate decreases from $2.5 \mathrm{~mm} / \mathrm{min}$ to $1.5 \mathrm{~mm} / \mathrm{min}$, it leads to the formation of specific onion rings.

These onion ring structures show us that adequate flow of materials and intermixing of the parent metals has taken place in a preferred manner in the fabricated joints [13]. But at the same time, in this arrangement, we can observe tunnel defects when the feed rate is further reduced to $0.5 \mathrm{~mm} / \mathrm{min}$ resulting due to excess amount of heat input. For the AZ80A/AZ91C joints, improvement in microstructural characteristics and flow of materials is observed as the feed rate decreases and joints with better quality are obtained at the feed rate of $0.5 \mathrm{~mm} / \mathrm{min}$.
These observations clearly indicate us that the microstructural characteristics are determined by process parameters and the arrangement of the materials on AS (advancing side) significantly influence the quality of the joints and the material flow behaviors especially in the stir zone.

\subsection{Material Flow Behaviour in Fabricated Joints}

The microstructural images of the AZ91C/AZ80A joints fabricated under process parameter combination of $3 \mathrm{kN}$ : $1.5 \mathrm{~mm} / \mathrm{min}$ : $800 \mathrm{rpm}$ are shown in the (Fig. 7a,b). These images show us that during the FSW process, the base materials on the AS and RS have undergone plastic deformation at the thermo mechanical transformation zone (TMTZ) due to the stirring action of the FSW tool. Moreover, proper mixing of these deformed materials has been taken place in the stir zone (SZ) resulting in the formation of grains having completely refined structure. This intermixing and transformation of plastically deformed materials is a characteristic feature of the FSW process $[14,15]$. Additionally, it can also be observed that the unevenly distributed grain structure present in the microstructure of both the base metals have been completely transformed into a uniformly distributed fine grain structure at the stir zone as shown in the (Fig. 7a,b).

One of the major reason for obtaining sound quality joints by keeping AZ91C on RS and AZ80A on AS when compared with the other arrangement is that, during the FSW process, it is easier for the metals to make their flow from the AS to RS rather than from the RS to AS. Another reason is that the chemical composition of the AZ80A Mg alloy, which makes it stronger and harder than AZ91C. But at the same time, AZ80A has poor plastic distortion ability when compared with that of AZ91C $\mathrm{Mg}$ alloy. As a result, when AZ91C is kept at AS, the flow of the plastically deformed material from RS to AS seems to be

TABLE 1

Macrostructural observations of dissimilar Mg alloy joints under various FSW process

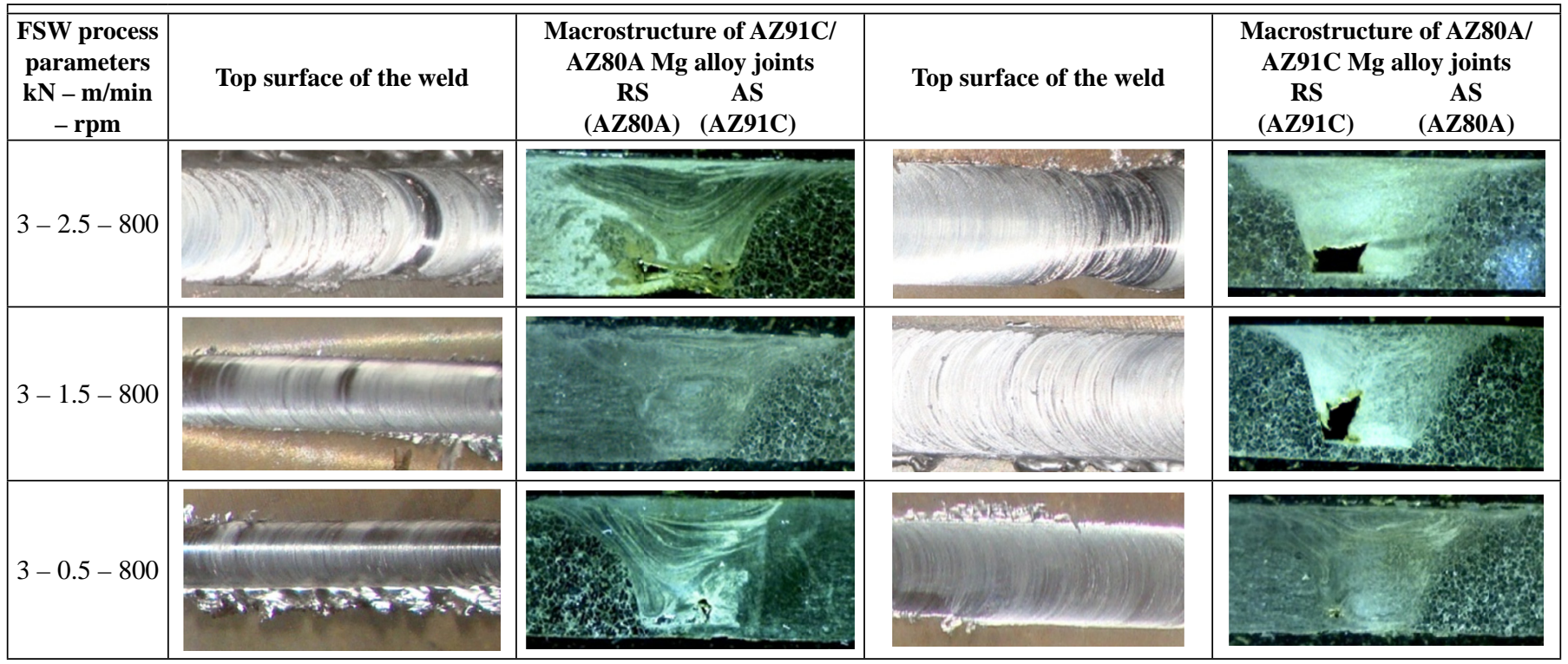



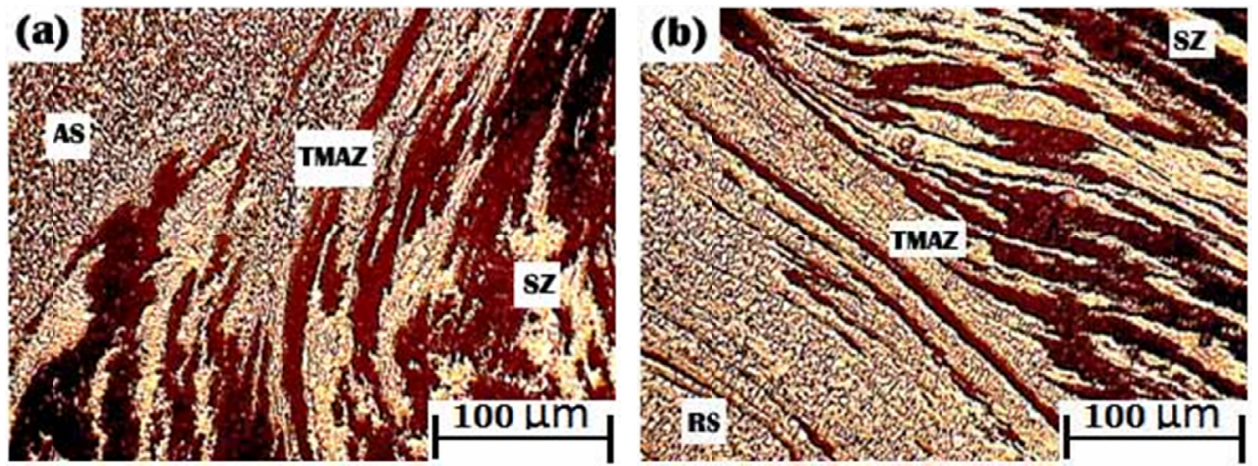

Fig. 7. Microstructural images of the AZ91C / AZ80A Mg alloy joints fabricated at $3 \mathrm{kN}: 1.5 \mathrm{~mm} / \mathrm{min}: 800 \mathrm{rpm}$ (a) as seen from the AS (b) as seen from the RS

more fluent as displayed in the Fig. 8a. At the same time, when AZ80A is at AS, the lower deformation capability of this alloy leads to the hindered flow back to AS as shown in the Fig. 8b. So, joints with AZ80A as their AS requires more amount of heat

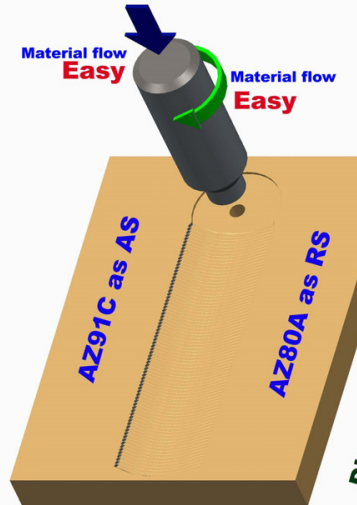

(a) AZ91C \& AZ80A joint

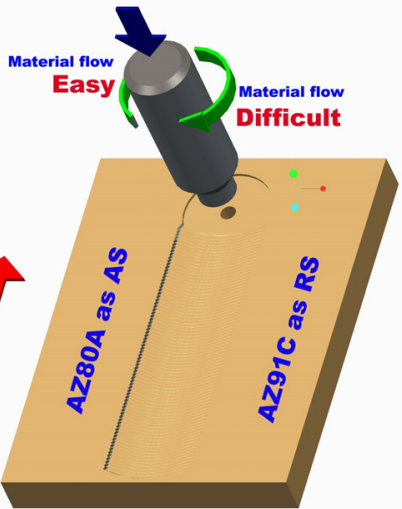

(b) AZ80A \& AZ91C joint
Fig. 8. Illustration of the flow of materials during FSW of dissimilar Mg alloys input to achieve the desired flow of materials to obtain joints with improved properties.

\subsection{Distribution of materials in the fabricated joints}

The scanning electron microscope (SEM) images and EDS (Energy Dispersive Spectroscopy) images of the base metals and the successfully fabricated AZ91C/AZ80A joints using FSW process are shown in (Fig. 9a-e). By comparing these images, it can be understood that the large coarse size grains with non uniform distribution present in both the dissimilar parent alloys have been completed transformed into evenly distributed, comparatively fine sized grains at the stir zone during the FSW process.

\subsection{Tensile properties of the Fabricated Joints}

The tensile strength of the AZ80A/AZ91C and AZ91C/ AZ80A joints fabricated under different FSW process parameters
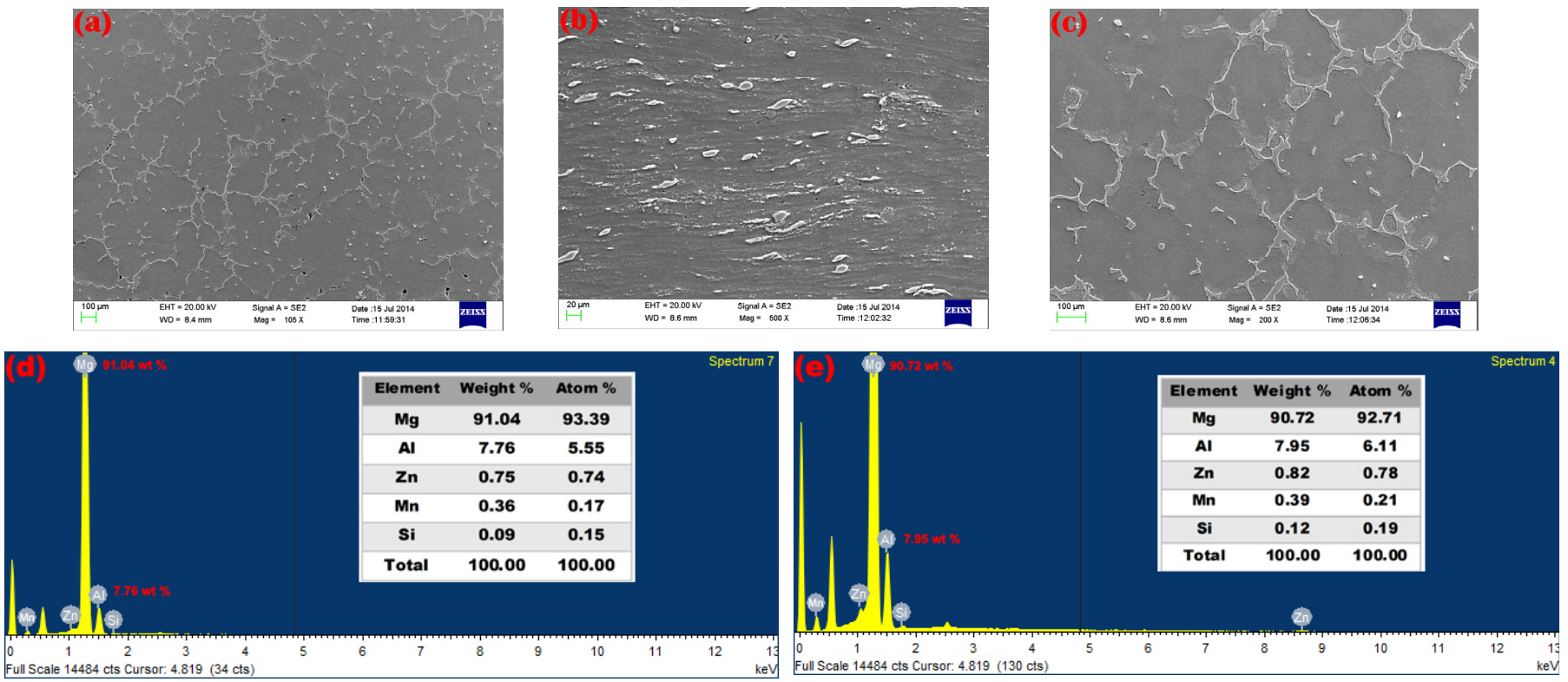

Fig. 9. SEM images of (a) Base metal: AZ80A Mg alloy (b) Base Metal: AZ91C Mg alloy and (c) fabricated AZ91C/AZ80A Joints and EDS images of (d) Base metal (AZ80A) and (e) fabricated AZ91C/AZ80A Joints 
are graphically portrayed in the Fig. 10. This graph reveals us that when the AZ91C Mg alloy is kept at AS, the tensile strength values of the joints fabricated under the process parameters of $3 \mathrm{kN}: 2.5 \mathrm{~mm} / \mathrm{min}$ : $800 \mathrm{rpm}$ and $3 \mathrm{kN}: 1.5 \mathrm{~mm} / \mathrm{min}$ : $800 \mathrm{rpm}$ were $214 \mathrm{MPa}$ and $236 \mathrm{MPa}$ respectively and the strength drastically reduced to $78 \mathrm{MPa}$ when the feed rate was reduced from $2.5 \mathrm{~mm} / \mathrm{min}$ to $0.5 \mathrm{~mm} / \mathrm{min}$. The reason is that at low feed rates, the excessive amount of heat input occurs which leads to smaller amount of tunnel defects thereby drastically reducing the thickness of the stir zone which makes the related tensile specimen to fracture easily during the tensile strength testing process. But in the case of joints fabricated by keeping AZ80A Mg alloy as AS, the tensile strength is found to increase with the decrease of feed rate i.e., from $2.5 \mathrm{~mm} / \mathrm{min}$ to $1.5 \mathrm{~mm} / \mathrm{min}$. At the same time, it should be noted that the maximum tensile strength value reached with these AZ80A/AZ91C joints is only $141 \mathrm{MPa}$. These results reveal us again that higher heat input is required for producing sound quality weldments for AZ80A/AZ91C joint arrangement when compared with the AZ91C/AZ80A joints. Moreover, these experimental results prove us that keeping AZ91C Mg alloy as AS seems to produce the satisfactory quality of joints compared with AZ80A Mg alloy on AS.

\section{Conclusions}

This paper experimentally reveals us that when AZ91C Mg alloy is kept at the advancing side (AZ91C/AZ80A joints), completely defect free joints were obtained with the majority of combinations of FSW process parameters when compared with that of obtaining sound quality weldments with AZ80A Mg alloy as the advancing side (AZ80A/AZ91C joints).

Moreover, it was also experimentally recorded that the flow of materials from AS to RS is easier compared with that of the flow from RS to AS. Additionally, the poor plastic distortion capability of the AZ80A Mg alloy creates the demand for a large amount of heat input in the case of AZ80A/AZ91C Mg alloy joints. As a result, unsatisfactory deformation of AZ91C at the stir zone occurs when it is kept on RS.

Further, this heat input requirement of AZ80A/AZ91C joints, also plays a significant role in drastically reducing the tensile strength of the fabricated joints. These results justify the fact that arrangement of different materials at AS have an important role in deciding the material flow, thereby influencing the joint properties and microstructural characteristics.

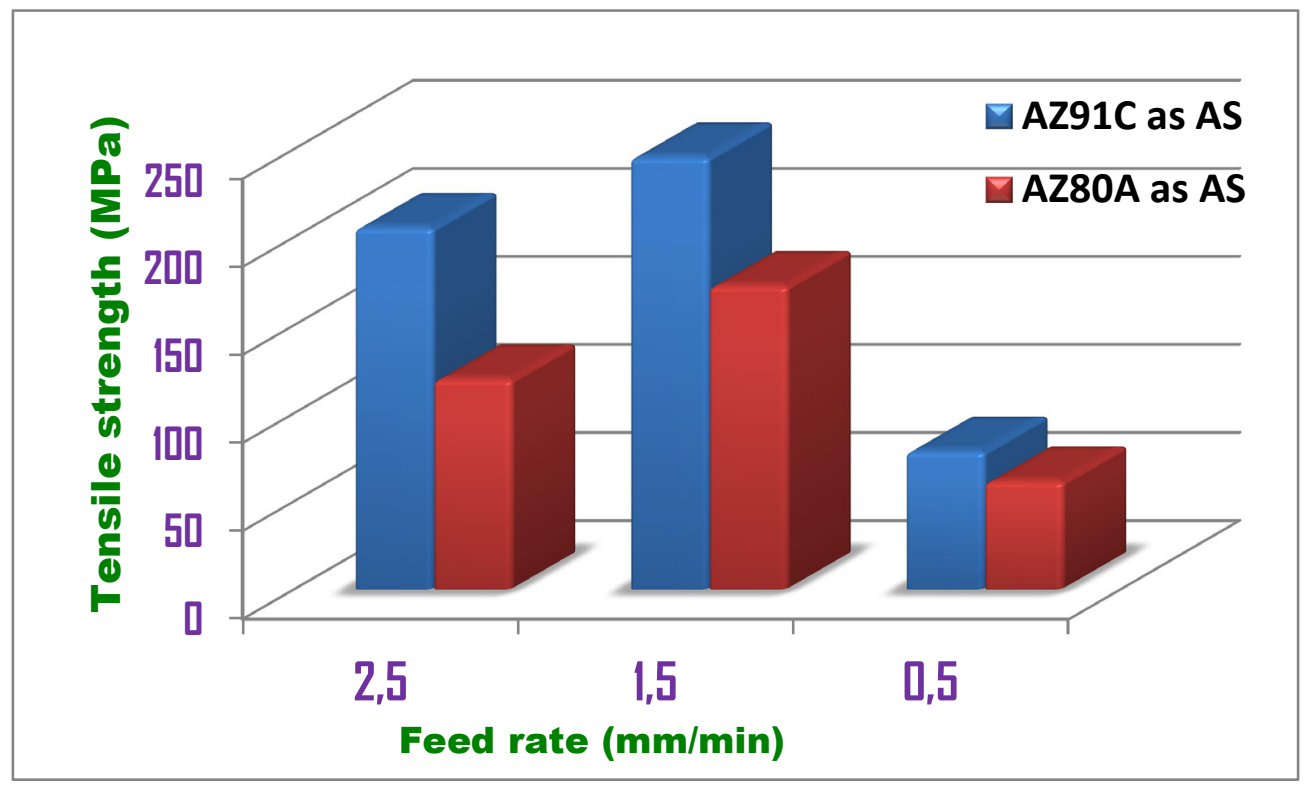

Fig. 10. Graphical illustration of tensile strength of the AZ80A/AZ91C and AZ91C/AZ80A joints fabricated under different FSW process parameters

Acknowledgement

The authors gratefully thank the Management and Mechanical Eng. Dept., S.A Engineering College, Chennai, India for providing the welding equipment facilities. The authors wish to express thanks to All India Council for Technical Education (AICTE) Govt. of INDIA, funded project (Grant No. 8023/RID/ RPS/037/2011-12) for sponsoring FSW machine.

\section{REFERENCES}

[1] H.S. Arora, H. Singh, B.K. Dhindaw, Wear behaviour of a Mg alloy subjected to friction stir processing, Wear 303, 65-77 (2013).

[2] P. Sevvel, V. Jaiganesh, Experimental Investigation on the impact of the Tool Material \& geometry in joining of Al 63400 Alloy using Friction Stir Welding Process, Applied Mechanics and Materials 592-594, 312-315 (2014).

[3] V. Jain, R.S. Mishra, A.K. Gupta, Study of $\beta$-precipitates and their effect on the directional yield asymmetry of friction stir processed 
and aged AZ91C alloy, Material Science and Engineering A 560, 500-509 (2013).

[4] A. Mohan, W. Yuan, R.S. Mishra, High strain rate superplasticity in friction stir processed ultrafine grained $\mathrm{Mg}-\mathrm{Al}-\mathrm{Zn}$ alloys, Material Science and Engineering A 562, $69-76$ (2013).

[5] P. Sevvel, V. Jaiganesh, Impact of process parameters during friction stir welding of AZ80A Mg alloy”, Science and Technology of Welding and Joining 21, 83-90 (2016).

[6] R.K. Kesharwani, S.K. Panda, S.K. Pal, Multi-Objective Optimization of Friction Stir Welding Parameters for Joining of Two Dissimilar Thin Aluminum Sheets, Procedia Materials Science 6, 178-187 (2014).

[7] P. Cavaliere, R. Nobile, F. Panella, A. Squillace, Microstructural Behaviour of 2024-7075 Aluminum Alloy Sheets Joined by Friction Stir Welding, International Journal of Machine Tools and Manufacture 46, 588-594 (2006),

[8] P. Sevvel, V. Jaiganesh, Effect of Tool Shoulder Diameter to Plate Thickness Ratio on Mechanical Properties and Nugget Zone Characteristics During FSW of Dissimilar Mg Alloys, Transactions of the Indian Institute of Metals 68, s41-s46 (2015).

[9] S. Yu, X. Chen, Z. Huang, Y. Liu, Microstructure and mechanical properties of friction stir welding of AZ31B magnesium alloy added with cerium, Journal of Rare Earths 28, 316-320 (2010).
[10] P. Sevvel, V. Jaiganesh, Characterization of mechanical properties and microstructural analysis of friction stir welded AZ31B Mg alloy thorough optimized process parameters, Procedia Engineering 97, 741-751 (2014).

[11] G.M. Xie, Z.Y. Ma, L. Geng, Effect of microstructural evolution on mechanical properties of friction stir welded ZK60 alloy, Materials Science and Engineering A 486, 49-55 (2008).

[12] R. Zeng, W. Dietzel, R. Zettler, J. Chen, K.U. Kainer, Microstructure evolution and tensile properties of friction-stir-welded AM50 magnesium alloy, Transactions of Nonferrous Metals Society of China 18, s76-s80 (2008).

[13] A.A.M. Silva, E. Arruti, G. Janeiro, E. Aldanondo, P. Alvarez, A. Echecerria, Material flow and mechanical behaviour of dissimilar AA2024-T3 and AA7075-T6 aluminium alloys friction stir welds, Materials \& Design 32, 2021-2027 (2011).

[14] V. Jaiganesh, P. Sevvel, Effect of Process Parameters in the Microstructural Characteristics and Mechanical Properties of AZ80A Mg Alloy during Friction Stir Welding, Transactions of the Indian Institute of Metals 68, 99-104 (2015).

[15] P. Sevvel, V. Jaiganesh, Impact of Tool Profile on Mechanical Properties of AZ31B Mg Alloy during FSW Using Optimized Parameters, FME Transactions 44, 43-49 (2016). 